\title{
The processing of consonants and vowels in reading: Evidence from the fast priming paradigm
}

\author{
HYE-WON LEE, KEITH RAYNER, and ALEXANDER POLLATSEK \\ University of Massachusetts, Amherst, Massachusetts
}

\begin{abstract}
We assessed the early encoding of consonant and vowel information in the reading of English, using the fast priming paradigm. With 30-msec prime durations, gaze durations on target words were shorter when preceded by high-frequency consonant-same primes (which shared consonant information with the target word; e.g., lake-like) than when preceded by vowel-same primes (which shared vowel information with the target word; e.g., line-like), but there were no priming effects for low-frequency primes. With 45-msec prime durations, however, there was no effect of prime frequency and gaze durations on target words were shortened equally when they were preceded by consonant-same primes and vowelsame primes, as compared with control primes (e.g., late-like). The results suggest that the processing of consonants is more rapid than that of vowels, providing further evidence for the distinction between consonant and vowel processing in the reading of English.
\end{abstract}

Recent studies have shown that consonants are processed more rapidly than vowels in English words (Berent \& Perfetti, 1995; H. Lee, Rayner, \& Pollatsek, 2001). Berent and Perfetti showed that a target word (rake) was better identified when followed by a consonant-preserving nonword mask (RIKK) than when followed by a vowelpreserving nonword mask (RAIB) at short exposure durations of targets and masks (15-30 or 30-30 msec). They accounted for the earlier consonant benefit within the framework of their two-cycles model, in which a representational and computational distinction between consonants and vowels was assumed. In the model, consonants are computed in the first cycle via a rapid and automatic process, and vowels are computed in the second cycle via a slower and controlled process. Although Berent and Perfetti's model suggests that the difference in processing between consonants and vowels is qualitative, such a drastic assumption is not necessary. Instead, if an important early stage in word encoding is getting to a phonological representation, consonants may be more useful in early processing in English, because they are relative "islands of reliability," as compared with vowels, in their grapheme-

The research reported here formed part of the first author's doctoral dissertation at the University of Massachusetts and was supported by Grant HD26765 from the National Institutes of Health. The second author was also supported by Research Scientist Award MH01255 from the National Institute of Mental Health. We thank Chuck Clifton, Marvin Daehler, Susan Duffy, Don Fisher, Ken Forster, Jung-Oh Kim, and two anonymous reviewers for their helpful suggestions. Also, we thank Barb Corbisier for her help in preparing the experimental sentences for this study. Correspondence concerning this article should be addressed to H.-W. Lee, who is now at the Laboratory for Low-Vision Research, Department of Psychology, University of Minnesota, 75 East River Rd., Minneapolis, MN 55455 (e-mail: hyewon@eye.psych.umn.edu). to-phoneme mappings (Carr \& Pollatsek, 1985). Our focus in the present article was to further explore the time course of the effect and how lexical factors interact with the phenomenon. This may shed some light on whether the consonant-vowel distinction is qualitative or quantitative.

Our prior experiments (H. Lee et al., 2001) employed a delayed-letter paradigm in which some of the letters of a target word were replaced by dashes at the beginning of an eye fixation during reading. After this brief initial period, the target word was normal. The critical finding was that the gaze duration ${ }^{1}$ on the target word was longer when consonant information was delayed for $30 \mathrm{msec}$ (readers saw $b u-b$ during the first $30 \mathrm{msec}$ of the fixation on $b u l b)$ than when vowel information was delayed for $30 \mathrm{msec}$ (readers saw $b$ - $l b$ for the first $30 \mathrm{msec}$ of the fixation). However, there was no difference between the two conditions when the delay was $60 \mathrm{msec}$. The greater delay effect for consonants during the initial $30 \mathrm{msec}$ indicates that consonants are initially processed more rapidly than vowels.

In contrast, Lukatela and Turvey (2000) reported no consonant-vowel differences, using a priming paradigm in which participants performed a lexical decision task on lowercase words and nonwords preceded by briefly presented $(14 \mathrm{msec})$ uppercase nonword primes. They found that lexical decisions for target words (glaze) were shortened equally when preceded by consonant-preserving (GLEZE) and vowel-preserving (GLAME) nonword primes, as compared with control primes (PROFT) that shared neither consonant nor vowel information with the target. They also found that consonant-preserving nonword primes (CLEP-clip) were less effective than consonant-andvowel-preserving primes (KLIP-clip) with 14-msec exposures (indicating an early role for vowel information). 
Table 1

Examples of Stimuli

Prime Type

\begin{tabular}{lccc} 
& & & \\
\cline { 2 - 4 } Target & Consonant-Same & Vowel-Same & Control \\
\hline like & lake & line & late \\
shop & ship & stop & step \\
\hline
\end{tabular}

Their results suggest that preserving consonant information has no special status.

We had two goals in the present experiment. First, we wanted to replicate our previous vowel-consonant finding in reading, using a different (fast priming) paradigm (Sereno \& Rayner, 1992). Second, as was noted above, we wanted to examine whether prime frequency plays a role in the early processing of vowels and consonants. A reason to think that prime frequency is relevant comes from Y. Lee, Binder, Kim, Pollatsek, and Rayner (1999). They found that high-frequency (HF) homophone primes facilitated the processing of target words, whereas lowfrequency (LF) homophone primes (and pseudohomophones) did not. This indicates that the early activation of phonological codes in reading is lexically modulated. Given that phonology is presumably the main locus of the consonant-vowel distinction, it is likely that the pattern of the consonant-vowel distinction is influenced by lexical factors.

Three variables were manipulated in the experiment. First, there were three kinds of primes, which varied in terms of consonant and vowel similarity to the target word. The consonant-same primes shared the same consonant with the target word in either the second or the third letter position, whereas the vowel-same primes shared the same vowel with the target word, also in either the second or the third letter position. The control primes were different from the target for both the second and the third letters (one of which was a vowel and one a consonant). All three primes were the same as the target in the other letter positions. Second, prime durations were short $(30 \mathrm{msec})$ or long (45 msec). Finally, primes were either HF or LF so that we could examine lexical involvement in the pattern of the consonant-vowel distinction. (See Table 1 for examples of stimuli.)

We employed the fast priming paradigm (Sereno \& Rayner, 1992) in which a string of random letters ( $c f g d)$ initially occupied a target location during reading (see Figure 1). When the readers' eyes crossed an invisible boundary (located just before the last letter of the word preceding the target word), the random letters were replaced by a prime (lake), which remained for either 30 or $45 \mathrm{msec}$ at the beginning of the fixation on the target word. The prime was then replaced by a target word (like), which remained until reading was completed. Gaze durations on target words were examined as a function of prime type, prime duration, and prime frequency. Our fast priming technique is similar in general outline to other fast priming techniques (Forster \& Davis, 1984), with similar results being obtained. The major advantage of our technique is that it can be used to study word identification during silent reading with minimal disruption of the reading process. A second advantage is that the fixation times obtained are appreciably shorter than manual or vocal latencies, so that we are capturing a more immediate response to the manipulation.

If an early distinction between vowels and consonants exists, the following should be observed. First, at the short prime duration, consonant-same primes should facilitate the processing of target words more than do control primes and vowel-same primes. Second, if there is little use of vowel information early in a fixation, vowel-same primes should facilitate processing no more than do control primes. Third, at the long prime duration, the advantage of consonant-same over vowel-same primes may disappear.

The effect of prime frequency is less clear, since there are plausible reasons for making opposite predictions. On the one hand, if something like the classic dual-route theory of phonology is assumed, it is possible that a consonantvowel difference would be found only for LF primes, because the lexical entry of an HF prime is accessed too rapidly to be influenced by effects in the slower assembled phonology route. Such a pattern would be roughly analogous to the well-known frequency $\times$ regularity interaction. On the other hand, early contact with the lexicon might be necessary for whatever the phonological process is that underlies the vowel-consonant effect in reading. As was mentioned above, Y. Lee et al. (1999) found that significant early excitation of phonologicalcodes in reading occurred only for HF words. Thus, it also seems plausible that the consonant-vowel difference might be obtained only for HF primes.

\section{METHOD}

\section{Participants}

Thirty-six undergraduate students at the University of Massachusetts participated in the experiment. They were native English speakers with normal vision; they were all paid to participate in the experiment.

\section{Apparatus}

Sentences were presented on a NEC 4FG monitor controlled by an 80486 microcomputer through a VGA board programmed to dis-

a. They don'|t $c f g d$ each other anymore.

$$
---->*
$$

b. They don'tt lake each other anymore.

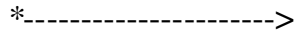

c. They don'|t like each other anymore.

Figure 1. An illustration of the fast priming paradigm. The vertical line indicates an invisible boundary, arrows indicate the movement of eyes, and the star indicates a fixation. 
Table 2

Gaze Durations (in Milliseconds) on the Target Word as a Function of Prime Type, Prime Duration, and Prime Frequency

\begin{tabular}{cccc}
\hline \multirow{2}{*}{$\begin{array}{c}\text { Prime } \\
\text { Duration (msec) }\end{array}$} & \multicolumn{3}{c}{ Prime Type } \\
\cline { 2 - 4 } & Consonant-Same & Vowel-Same & Control \\
\hline \multicolumn{4}{c}{ High-Frequency Prime } \\
30 & 322 & 354 & 345 \\
45 & 347 & 342 & 377 \\
\multicolumn{4}{c}{} \\
30 & Low-Frequency Prime & \\
45 & 357 & 348 & 354 \\
\hline
\end{tabular}

Note-The reported gaze durations have the prime duration subtracted from them.

play 140 lines of pixels in EGA Mode 10; the refresh rate was $5 \mathrm{msec} / \mathrm{screen}(200 \mathrm{~Hz})$. All the sentences were 80 characters or fewer and were displayed on a single line. The participants were seated $61 \mathrm{~cm}$ from the monitor, and 3 characters equaled $1^{\circ}$ of visual angle. Viewing was binocular, with eye movements being recorded from the right eye by a Dual Purkinje Eyetracker (resolution $<10$ min of arc), with its signal sampled every millisecond by the computer.

\section{Materials and Design}

Each target word was embedded in one of 72 experimental sentences, 36 in the HF prime condition and 36 in the LF prime condition. For half of the target words (and matched prime words) in each frequency condition, the second and third letters were in the order of vowel-consonant; for the other half, they were in the order of consonant-vowel. This counterbalancing equates the letter position of consonants and vowels in the target words. For each target word, there were three kinds of primes (consonant-same prime, vowel-same prime, and control prime), each matched in length to the target word. The mean word frequency (Francis \& Kučera, 1982) of the HF primes was 178 (consonant-same, 179; vowelsame, 178; control, 179), and the mean frequency of the LF primes was 7 (consonant-same, 6; vowel-same, 8; control, 8). The mean frequency of the targets was matched for the two frequency conditions (HF condition, 124; LF condition, 115). All the target and prime words were either four or five letters long. Two prime durations $^{2}$ (30 and $45 \mathrm{msec}$ ) were employed. The sentences were presented in a different random order, and the readers saw each target word in only one of the six conditions ( 3 prime types $\times 2$ prime durations) in each frequency condition, with the assignment of the stimuli to conditions counterbalanced across readers. The stimuli are presented in the Appendix.

\section{Procedure}

The participants read 10 practice and 72 experimental sentences as their eye movements were recorded. Prior to each trial, the experimenter confirmed that the eyetracker was accurately calibrated.

\section{RESULTS}

Data were excluded from the analyses by using criteria outlined in Sereno and Rayner (1992). ${ }^{3}$ Analyses of variance (ANOVAs) and planned comparisons based on subject $\left(F_{1}\right)$ and item $\left(F_{2}\right)$ variability were conducted on gaze durations on the target words (with prime duration subtracted out in order to assess the time the target was fixated after it appeared; see Table 2).
A 3 (prime type) $\times 2$ (prime duration) $\times 2$ (prime frequency) ANOVA revealed a main effect of prime type $\left[F_{1}(2,70)=7.21, M S_{\mathrm{e}}=2,068, p<.005 ; F_{2}(2,140)=\right.$ $\left.7.44, M S_{\mathrm{e}}=2,514, p<.001\right]$ and a prime type $\times$ duration interaction $\left[F_{1}(2,70)=3.57, M S_{\mathrm{e}}=3,081, p<.05\right.$, although $\left.F_{2}(2,140)=1.82, M S_{\mathrm{e}}=1,904, p>.1\right]$. No other effects were significant.

Separate 2 (prime type: consonant-same, vowel-same) $\times 2$ (prime frequency) ANOVAs were conducted on the data from the 30- and 45-msec durations. These analyses revealed an interesting difference in the pattern of interaction at the two durations. Specifically, there was a significant interaction between prime type and frequency at the 30-msec duration $\left[F_{1}(1,35)=9.00, M S_{\mathrm{e}}=1,682, p=\right.$ $\left..005 ; F_{2}(1,70)=4.88, M S_{\mathrm{e}}=2,324, p<.05\right]$, but not at the 45 -msec duration $\left(F_{\mathrm{S}}<1\right)$. Neither main effect was significant at either duration $(p s>.1)$.

More specific were the planned comparisons. First, for HF primes, at the $30-\mathrm{msec}$ duration, consonant-same primes had a $23-\mathrm{msec}$ benefit over control primes in facilitating the target $[t(35)=2.48, S E=9 \mathrm{msec}, p<.02$; $t(35)=2.59, S E=9 \mathrm{msec}, p<.02]$, whereas vowelsame primes showed no benefit $(-9 \mathrm{msec})$ over controls $(t \mathrm{~s}<1)$. More crucially, consonant-same primes had a 32msec benefit over vowel-same primes at the 30 -msec duration $[t(35)=3.11, S E=10 \mathrm{msec}, p<.005 ; t(35)=2.48$, $S E=13 \mathrm{msec}, p<.02]$. In contrast, at the 45 -msec duration, both consonant-same $(30 \mathrm{msec})$ and vowel-same (35 msec) primes had significant benefits over control primes $[t(35)=2.05, S E=15 \mathrm{msec}, p<.05 ; t(35)=2.13$, $S E=14 \mathrm{msec}, p<.05 ;$ and $t(35)=2.14, S E=16 \mathrm{msec}$, $p<.05 ; t(35)=2.14, S E=16 \mathrm{msec}, p<.05$, respectively]. The 5-msec difference between consonant-same and vowel-same primes was not significant $(t \mathrm{~s}<1)$.

For LF primes, there was no difference in any comparison of the three prime types at the 30-msec duration $(t \mathrm{~s}<1)$, whereas at the 45 -msec duration, both consonantsame $(26 \mathrm{msec})$ and vowel-same $(31 \mathrm{msec})$ primes showed significant benefits over control primes $[t(35)=2.21$, $S E=12 \mathrm{msec}, p<.05 ; t(35)=2.13, S E=12 \mathrm{msec}, p<$ .05 ; and $t(35)=3.16, S E=10 \mathrm{msec}, p<.005 ; t(35)=$ $2.49, S E=12 \mathrm{msec}, p<.02$, respectively]. The difference between consonant-same and vowel-same primes was not close to significant $\left(t_{\mathrm{s}}<1\right)$.

Our key finding, then, was that there was an early distinction between consonant and vowel processing in the $\mathrm{HF}$ condition. Several additional items analyses were conducted on this key comparison. First, we examined the influence of letter position (vowel-consonant vs. consonantvowel order in the second and third letters). For HF primes, the differences between consonant-same and vowel-same primes at the $30-\mathrm{msec}$ duration were 25 and $31 \mathrm{msec}$ for words with the vowel-consonant order and for words with the consonant-vowel order, respectively $(F<1$, for the interaction of order with the difference in priming effect). There was similarly little difference between the two orders ( -5 and $-9 \mathrm{msec})$ for the LF primes at $30 \mathrm{msec}$. 
Second, we examined whether the early benefit of consonant-same primes could be due to consonant-same primes being more visually similar to the target than are vowel-same primes. Because consonants are visually more varied than vowels, owing to diverse height, the typical consonant-same pairs (e.g., lake-like) are plausibly more visually similar than the typical vowel-same pairs (e.g., line-like). Thus, it is possible that the early disadvantage of vowel-same primes might have been partially due to higher visual dissimilarity between vowel-same primes and targets. ${ }^{4}$ To test this, items were divided into a height-same group (in which the height of the consonants in vowelsame primes and targets was the same; nice-nine, stop-shop) and a height-different group (in which they were different; bold-bond, scar-star). If the disadvantage of vowel-same primes was due to higher visual dissimilarity to the target, ${ }^{5}$ the difference between consonant-same and vowel-same primes should be attenuated in the heightsame group. For a total of 36 quadruples in the HF condition, 17 were categorized as height-same and 19 as heightdifferent, and for the 36 quadruples in the LF condition, 14 were categorized as height-same and 22 as heightdifferent. The observed differences between consonantsame and vowel-same primes were $24 \mathrm{msec}$ (heightsame) and $32 \mathrm{msec}$ (height-different) for HF primes and $-14 \mathrm{msec}$ (height-same) and $-3 \mathrm{msec}$ (height-different) for LF primes. For HF primes at the $30-$ msec duration, there was a main effect of prime type $\left[F(1,34)=5.86, M S_{\mathrm{e}}=\right.$ $2,369, p<.05$ ], but neither the main effect of height nor the interaction was significant $\left(F_{\mathrm{S}}<1\right)$. These results thus indicate that the early benefit of consonant-same primes over vowel-same primes was not dependent on the visual similarity between primes and targets.

Third, we examined whether the difference between consonant-same and vowel-same primes for the HF primes could have been related to the fact that the vowels were inconsistently pronounced for seven of them (e.g., bond/ bold). (There were five such pairs in the LF items as well.) When the 29 items in which the vowels in targets and their vowel-same primes were consistently pronounced were analyzed separately, means in the 30 -msec prime condition were 324,347 , and $347 \mathrm{msec}$ for the consonantsame, vowel-same, and control prime conditions, respectively, or within $3 \mathrm{msec}$ of the differences observed in the principal item analysis. Possibly because of the reduced power of having fewer items, the difference between consonant-same and vowel-same conditions was only marginally significant $[t(28)=1.85, p=.075]$, but the difference between consonant-same and control conditions was significant $[t(28)=2.09, p<.05] .^{6}$

The major results of the experiment can be summarized as follows. First, at the 30-msec duration, consonant-same primes facilitated processing targets more than did either vowel-same primes or control primes; in contrast, vowelsame primes facilitated processing targets no more than did control primes at this duration. This pattern, however, occurred only for HF primes; for LF primes, there was no difference in any comparison of the three prime types. Second, at the 45-msec duration, both consonant-same and vowel-same primes facilitated targets more than did control primes for both HF and LF primes.

\section{DISCUSSION}

The present data provide further evidence of a temporal difference in processing consonants and vowels in English: Consonant processing occurs more rapidly than vowel processing, as was indicated by shorter gaze durations on target words when primes and targets shared consonants in the second and third letter positions than when they shared vowels in those positions. However, lexical factors played a role, since the consonant-vowel differences occurred only for HF primes.

The fact that the pattern of the consonant-vowel difference was independent of the visual properties of consonants and vowels indicates that the consonant-vowel distinction is phonologically driven, rather than orthographically driven. Additional support for the phonological locus of the consonant-vowel distinction comes from a comparison of experiments in English and Italian. In Italian, Colombo (2000) obtained an early vowel advantage, using the same paradigm as Berent and Perfetti (1995). Given that the alphabets in the two languages are virtually identical, the most plausible reason for this difference is that Italian, unlike English, has extremely regular grapheme-phoneme correspondences for both vowels and consonants (Colombo, 2000). However, our analyses in which the effects of vowel sound agreement between prime and target and vowel sound consistency were examined suggest that the vowel-consonant distinction may not lie with the inconsistencies of the actual vowel sounds encountered but with more ingrained processing strategies caused by the generally greater inconsistency of vowels in English.

An important finding in our experiment is that the consonant-vowel difference is lexically modulated: The early benefit of consonant-same primes was obtained only with HF primes. This suggests that the consonantvowel difference was the result of an interaction between the indirect route to phonology (grapheme-phoneme translation) and the lexical route to phonology. There are three plausible explanations for such an interaction. One is that the lack of the consonant-vowel difference for LF primes might be due to an inhibitory effect of HF neighbors. Pollatsek, Perea, and Binder (1999) found that increasing the number of higher frequency neighbors of a word (when the total number of neighbors was controlled) produced an inhibitory effect on word identification in reading. In our experiment, the mean number of higher frequency neighbors (those whose frequency was higher than that of the prime) was 5 for LF primes and 1 for HF primes, although both sets of primes had an equal mean total number of neighbors (10). It is plausible that a general reduction in the efficiency of processing LF primes 
owing to interference from HF neighbors could have been responsible for the absence of a consonant-vowel difference for LF primes.

The second possibility is to assume that there is a deep interaction between the two routes in the construction of a phonologicalcode. The nonlexical route to phonology is dominant in reading, but that its early outcomes have a poor representation (owing to insufficient resources) that can be strengthened by the activation from the lexical route (Frost, 1998). Suppose that at $30 \mathrm{msec}$ from prime onset, only partial phonological codes are computed from the prime (mostly for consonants), but the representations of partial codes are too weak to have any priming effect on their own. However, if the prime is of a high enough frequency, activation from the lexical representation of the prime spreads toward the consonants, strengthening their representations and allowing them to prime the target. Lower frequency primes may not have this power to strengthen the consonant representations, either because their lexical entry may be accessed slower than that of HF primes or because their lexical activation may be weaker (or both). In contrast, suppose that at $45 \mathrm{msec}$ from prime onset, the inventory of phonological outcomes includes both consonants and vowels and they are fully represented. Thus, both vowels and consonants should have full priming power and do not need strengthening from the lexical entry. Moreover, the lexical entry for both HF and LF primes may now be fully developed enough to provide useful additional activation to the representation in the indirect route.

The third account of the null effect with LF primes is based on the ratio of prime and target frequencies. In our experiment, the mean frequency of LF Primes (7) was lower than that of their matched targets (115), but the mean frequency of the HF primes (178) was higher than that of their matched targets (124). Analogous to the first account of lexical interference from higher frequency neighbors, there might be backward interference from the target to the LF prime, reducing the amount of activation the LF prime gives to the activated consonants. This would lead to a weak or null effect of a brief prime with the same consonants as the target.

The pattern of results in the present study is not exactly the same as that in any of the prior studies. Lukatela and Turvey (2000), using nonword primes, obtained no difference between consonant and vowel primes at brief durations, consistent with our failure to find a difference for LF primes. However, they obtained priming from both consonants and vowels, rather than priming from neither, in contrast to our results with LF primes at $30 \mathrm{msec}$. On the other hand, Berent and Perfetti (1995) obtained the consonant-vowel difference with nonword primes, and H. Lee et al. (2001) obtained a difference with partial word primes (both types of primes having zero frequency). One possible account for the discrepancy between the studies is that the extent of lexical modulation may interact with differences in experimental situations (including tasks, measurements, and stimuli). For example, lexical in- volvement in the nonlexical pathway may be stronger in a silent reading task, as compared with other tasks, making the consonant-vowel effect more vulnerable to frequency. Our previous experiments (H. Lee et al., 2001) and the present experiment employed similar silent reading tasks, but the stimuli were different in several aspects. For example, the targets used by H. Lee et al. generally had fewer neighbors than did the targets used in the present experiment and, thus, the partial word information in the prime may have significantly activated the lexical representation of the target. The best interpretation of our data would be that lexical factors play a role in the modulation of the consonant-vowel effect but that the extent of their role depends on the specifics of the experiment. Moreover, the fact that the vowel-consonant effect is modulated by lexical factors, task differences, and language suggests that the processing distinction between vowels and consonants is not qualitative.

In summary, this experiment provides further evidence that the early processing of consonants is more rapid than that of vowels in the reading of English. It also demonstrates that the consonant-vowel distinction in early processing is influenced by lexical factors (frequency), since the benefit of consonant-same primes occurred only with HF primes.

\section{REFERENCES}

Berent, I., \& Perfetti, C. A. (1995). A rose is a reez: The two cycles model of phonology assembly in reading English. Psychological Review, 102, 146-184.

Carr, T. H., \& Pollatsek, A. (1985). Recognizing printed words: A look at current models. In D. Besner, T. G. Waller, \& G. E. MacKinnon (Eds.), Reading research: Advances in theory and practice (Vol. 5, pp. 2-82). Orlando, FL: Academic Press.

Colombo, L. (2000). The assembly of phonology in Italian and English: Consonants and vowels. In A. Kennedy, R. Radach, D. Heller, \& J. Pynte (Eds.), Reading as a perceptual process (pp. 377-398). Amsterdam: North-Holland.

Forster, K. I., \& DAVIS, C. (1984). Repetition priming and frequency attenuation in lexical access. Journal of Experimental Psychology: Learning, Memory, \& Cognition, 10, 680-698.

FrAnCIS, W. N., \& KUČERA, H. (1982). Frequency analysis of English usage: Lexicon and grammar. Boston: Houghton Mifflin.

Frost, R. (1998). Toward a strong phonological theory of visual word recognition: True issues and false trails. Psychological Bulletin, 123, 71-99.

Lee, H., Rayner, K., \& Pollatsek, A. (2001). The relative contribution of consonants and vowels to word identification during reading. Journal of Memory \& Language, 44, 189-205.

Lee, Y., Binder, K. S., Kim, J., Pollatsek, A., \& Rayner, K. (1999). Activation of phonological codes during eye fixations in reading. Journal of Experimental Psychology: Human Perception \& Performance, 25, 948-964.

Lukatela, G., \& Turvey, M. T. (2000). An evaluation of the two cycles model of phonology assembly. Journal of Memory \& Language, 42, 183-207.

Pollatsek, A., Perea, M., \& Binder, K. S. (1999). The effects of neighborhood size in reading and lexical decision. Journal of Experimental Psychology: Human Perception \& Performance, 25, 11421158.

Sereno, S. C., \& RAYner, K. (1992). Fast priming during eye fixations in reading. Journal of Experimental Psychology: Human Perception \& Performance, 18, 173-184. 
Treiman, R., Mullennix, J., Bijeljac-Babic, R., \& RichmondWeLty, E. D. (1995). The special role of rimes in the description, use, and acquisition of English orthography. Journal of Experimental Psychology: General, 124, 107-136.

\section{NOTES}

1. Gaze duration is the sum of all fixations on a word made prior to moving to another word. It is contingent on the word's being fixated on the first pass through the sentence.

2. Two display changes occurred in the experiment. First, when an eye movement crossed the invisible boundary (see Figure 1), the computer replaced the random letter string with the prime word. Because this change occurred during a saccade, the participants did not notice it. The prime remained in the target location for 30 or $45 \mathrm{msec}$ (measured from the onset of fixation, not when the eyes crossed the boundary) and was then replaced by a target word. This second change, which occurred during a fixation, was often noticed by the participants. The target word remained in place while the participants finished reading the sentence. Because the display was a raster device (with a cycle time of $6.25 \mathrm{msec}$ ), the actual prime durations were actually somewhat larger than the nominal prime durations. That is, the signal to make a display change occurred either 30 or $45 \mathrm{msec}$ after the beginning of the fixation. However, the actual display change occurred when the electron beam actually "painted" the target word, which ranged from less than $1 \mathrm{msec}$ after the display change signal up to $6.25 \mathrm{msec}$ after the signal. Thus, the actual prime intervals were $30-36 \mathrm{msec}$ for the nominal 30 -msec prime duration and 45-51 msec for the nominal 45-msec prime duration.

3. In fast priming experiments, data can be lost for a number of reasons (see Sereno \& Rayner, 1992): (1) The eyetracker can lose track of the reader's eye; (2) the reader can skip over the target word, which includes the space before the word and the word itself; (3) the eyes can trigger the boundary change but remain on the word before the target (usually the last letter of this word); (4) the onset of the prime may not coincide with the onset of the fixation; (5) the first fixation on the target word may be less than $100 \mathrm{msec}$, or a first-pass fixation (one not resulting from a regression) may be greater than 700 (these values include the prime duration); (6) a first-pass fixation on the target word may be the last fixation recorded in the sentence. In the present experiment, $70 \%$ of the data were usable.

4. However, it is not clear why this confounding would not also affect the pattern at the longer prime duration.

5 . The visual dissimilarity of the two different vowels in consonantsame primes and the target is relatively low, because all vowels are short in height; the only exception, $y$, was not used in the stimuli.

6 . A related question is whether a general inconsistency in vowel pronunciation (not necessarily reflected by the consistency of the prime and the target tokens used in the experiment) had an effect on the size of the consonant-prime vowel-prime difference observed for HF items at $30 \mathrm{msec}$. To answer this question, we used a vowel consistency measure that had been tabulated using a large corpus of words with CVC pronunciations (Treiman, Mullennix, Bijeljac-Babic, \& RichmondWelty, 1995). However, only 19 each of the HF and LF targets appeared in the corpus (e.g., bond and lift are not pronounced as CVCs). Nevertheless, we correlated this measure (which gets larger, the higher the consistency) with the difference between vowel-prime and consonant prime conditions separately for the 19 targets in each of the HF and LF conditions. The pattern of data was somewhat strange, since there were small positive correlations, for both HF and LF targets, between vowel consistency and the vowel-consonant difference at the 30-msec prime duration (.24 for HF targets and .20 for LF targets) and somewhat larger negative correlations at the $45-\mathrm{msec}$ prime duration (-.34 and -.48). It thus appears that, at the shorter prime duration, the effect is opposite to what one might predict (i.e., greater vowel consistency makes the vowel-consonant difference bigger) and there might be the expected effect at the longer prime duration. Of course, there was no overall difference at the longer prime duration between vowel-same and consonantsame primes, so the pattern of results is difficult to interpret. However, there does not seem to be any reason to conclude that vowel consistency has a strong effect on the vowel-consonant difference observed at the 30-msec prime duration for the HF items.

APPENDIX

Experimental Stimuli Used in the Experiment

\begin{tabular}{|c|c|c|c|}
\hline \multirow[b]{2}{*}{ Sentences (Targets Italicized) } & \multicolumn{3}{|c|}{ Primes } \\
\hline & C-Same & V-Same & Control \\
\hline \multicolumn{4}{|c|}{ High-Frequency Prime Condition } \\
\hline The strong bond between them was obvious. & band & bold & bird \\
\hline Chuck was known for his firm grasp in a handshake. & form & film & foam \\
\hline The many cows in the herd grew restless. & hard & held & hand \\
\hline Jim found there was less flour than he thought. & loss & legs & laws \\
\hline She helped him lift the heavy box. & left & list & lost \\
\hline They don't like each other anymore. & lake & line & late \\
\hline It's easy to be male in our society. & mile & made & more \\
\hline There were nine cups left out of the original twelve. & none & nice & note \\
\hline There were none of the cookies left. & nine & nose & name \\
\hline The best pick was made by the youngest child. & pack & pink & park \\
\hline The chef had her assistants pare the apples. & pure & pale & pile \\
\hline In the distant past things were much different. & post & part & port \\
\hline She got a small role in the movie. & rule & rode & race \\
\hline His clever ruse fooled them all. & rose & rule & ride \\
\hline The giant sale attracted many shoppers. & sole & safe & size \\
\hline She hummed the tune over and over. & tone & tube & tale \\
\hline The moon began to wane last week. & wine & wave & wide \\
\hline The wolf was tame since they had raised it from birth. & time & take & tone \\
\hline The smell of freshly mowed grass means spring to me. & gross & glass & guess \\
\hline The final score was in our team's favor. & scare & shore & stare \\
\hline The teacher made the children share the crayons. & shore & stare & store \\
\hline Nancy found the pretty shell on the beach. & shall & smell & small \\
\hline
\end{tabular}




\begin{tabular}{|c|c|c|c|}
\hline \multirow[b]{2}{*}{ Sentences (Targets Italicized) } & \multicolumn{3}{|c|}{ Primes } \\
\hline & C-Same & V-Same & Control \\
\hline We boarded the huge ship in New York. & shop & slip & snap \\
\hline The curious shop sold items from around the world. & ship & stop & step \\
\hline He had a long hour on the shore of the lake. & share & store & stare \\
\hline The tall girl was jealous of her short sister. & shirt & sport & start \\
\hline The baked bread smell filled the warm kitchen. & small & shell & shall \\
\hline She was embarrassed to find that her slip was showing. & slap & skip & stop \\
\hline One of his farm chores was to feed slop to the hogs. & slip & stop & step \\
\hline The engineers claimed the span of the bridge was too wide. & spin & scan & skin \\
\hline He cleaned the horse's stall after brushing him down. & still & small & skill \\
\hline When he got lost, the north star led him to safety. & stir & scar & spur \\
\hline The lawyer's cold stare left the defendant uneasy. & store & share & score \\
\hline After all this time, she was still studying for the test. & stall & skill & shall \\
\hline The recipe called for vegetable stock instead of beef. & stick & shock & snack \\
\hline The teacher had them stop immediately. & step & shop & ship \\
\hline \multicolumn{4}{|c|}{ Low-Frequency Prime Condition } \\
\hline Jessica wanted to get $b a c k$ as soon as possible. & buck & bark & bulk \\
\hline John had to loosen his leather belt after the big meal. & bolt & bent & bust \\
\hline They had their first date a year ago. & dote & daze & dice \\
\hline The house was located at the left side of the road. & loft & lent & lust \\
\hline On his final dive he got a perfect score. & dove & dice & dole \\
\hline The swans had one $d u c k$ swimming in the pond with them. & dock & dusk & dank \\
\hline Nobody knew the fate of the missing child. & fete & fake & fuse \\
\hline Down the narrow lane was a small cottage. & lone & lame & lobe \\
\hline The little boy got lost in the woods. & lust & loft & lent \\
\hline Amy had a brilliant mind and loved to read. & mend & mild & meld \\
\hline The old silver mine was about to cave in. & mane & mike & mole \\
\hline The most pious monk never spoke a word. & $\operatorname{mink}$ & mock & mask \\
\hline They watched the balloon rise into the morning sky. & ruse & rime & rude \\
\hline Karen felt quite sick but went to work anyway. & sock & silk & sank \\
\hline The building site had everything they wanted. & sate & sine & sore \\
\hline His difficult task prevented him from going out that night. & tusk & tank & tick \\
\hline She assured him that the time would eventually be right. & tome & tide & tune \\
\hline They enjoyed the wine and pasta. & wane & wile & wade \\
\hline The tile had a small chip out of one corner. & chop & clip & clap \\
\hline The tailor took a small clip out of the fabric. & clap & chip & chap \\
\hline Barb set her alarm clock incorrectly. & click & chock & chick \\
\hline The farmer was pleased with the good crop this year. & crap & chop & clap \\
\hline The accident left his shin with a nasty scrape. & shun & spin & swan \\
\hline Julie was pleased with the shine left from the polish. & shone & spine & stone \\
\hline Sandy's careful shot hit the center of the target. & shit & slot & spit \\
\hline Carol showed great skill in sculpting. & skull & spill & swell \\
\hline Her response was a sharp slap across his face. & slop & swap & snip \\
\hline A surprising loud snap told us the board had broken. & snip & swap & slop \\
\hline The car's spare tire was also flat. & spore & snare & snore \\
\hline The witch cast the magic spell on the princess. & spill & swell & skull \\
\hline The invited guest spoke at length. & spike & stoke & slake \\
\hline His favorite sport was football. & spurt & snort & smart \\
\hline He got a mustard spot on his favorite shirt. & spit & slot & slit \\
\hline Books were piled in a neat stack in the corner. & stuck & slack & snick \\
\hline The new rubber address stamp made paying bills easier. & stump & swamp & slump \\
\hline The tasty midnight snack hit the spot. & snick & shack & speck \\
\hline
\end{tabular}

Note-The target words are italicized here, but not in the actual experiment.

(Manuscript received January 4, 2001;

revision accepted for publication October 9, 2001.) 